\title{
The Effect of Interest and Engagement in Learning Science on Adults' Scientific Competency and Environmental Action
}

\author{
Yi-Ting Pan ${ }^{1}$, Kuay-Keng Yang ${ }^{2}$, Zuway-R Hong ${ }^{1}$, Huann-Shyang Lin ${ }^{2 *}$ \\ ${ }^{1}$ Institute of Education, National Sun Yat-sen University, Kaohsiung, TAIWAN \\ ${ }^{2}$ Center for General Education, National Sun Yat-sen University, Kaohsiung, TAIWAN \\ Received 4 January 2018 - Revised 11 April 2018 - Accepted 29 April 2018
}

\begin{abstract}
Although existing research has documented the significant relationship among student interest, engagement, and learning outcome, limited studies have investigated how adults' interest and engagement in learning science are related to their scientific competency and environmental action. This study used 2012 and 2015 national datasets which were collected from face-to-face interviews representing how the interest and engagement of Taiwan citizens in understanding and exposure to science in society synergistically interact with their scientific competency and environmental action. Results showed that engagement in learning is more predictive to scientific competency and environmental action than interest. In addition, engagement in visiting science museums appears to be a superior venue for promoting adults' environmental action than watching science related TV programs. These findings reveal an effective strategy of promoting adult environmental action through science communication and the importance of deep science learning.
\end{abstract}

Keywords: affective factors, free-choice learning, sustainability, adult education, scientific literacy

\section{INTRODUCTION}

The environmental challenges facing the world today such as ozone depletion, air pollution, marine debris, and global warming, require radical changes in human environmental behaviors and actions. In order to make such changes possible, it is imperative to identify what factors are associated with environmental behaviors and actions. Previous studies have posited that a wide range of affective and social factors synergistically impact scientific competency and environmental awareness (Jack, Lin, \& Yore, 2014; Lin, Hong, \& Huang, 2012) and action (Stapleton, 2015). In addition, environmental and science educators have devoted much attention to the venue of non-school settings, where people actually spend the majority of their time for enjoyment and relaxation (Bell, Lewenstein, Shouse, \& Feder, 2009). In spite of the importance of compulsory education, on average a typical citizen spends only $3 \%$ of their life time in school or formal educational settings. On the other hand, adults attribute roughly half of their science learning to free-choice learning experiences (Falk, Storksdieck, \& Dierking, 2007). These experiences play an important role in not only impacting adults' everyday behavior and lifestyle choices, but also promoting their adoption of environmentally sustainable actions (Ballantyne \& Packer, 2011). Therefore, citizens' choices of engagement in leisure time learning may have a potential or predictive effect on their scientific competency and environmental action. Although research studies have documented that engagement and interest in science learning have positive effect on students' learning outcomes (Jack et al., 2014; Su, Ding \& Lai, 2017), it reveals that most of the studies focused on students' science learning in formal settings, few studies have discussed public citizens' science learning in informal settings.

The results of large-scale studies provide insights which have the potential to affect policy making and educational reform. For example, large-scale studies investigating the science learning outcomes using data collected from Trends in International Mathematics and Science Survey (TIMSS) measure how well $4^{\text {th }}$ grade and

(C) 2018 by the authors; licensee Modestum Ltd., UK. This article is an open access article distributed under the terms and conditions of the Creative Commons Attribution License (http://creativecommons.org/licenses/by/4.0/). \syvia@staff.nsysu.edu.tw $\square$ kuaykeng@gmail.com $\square$ a3803429@gmail.com

\uannlin@mail.nsysu.edu.tw (*Correspondence) 


\section{Contribution of this paper to the literature}

- While previous studies have focused on students' interest, engagement, and learning outcomes in science, limited attention of large scale study has been paid on adults' science learning and outcome.

- By comparing two cycles of national survey on public citizens' science learning experience and outcome, this study provides fresh insights into the changing pattern and trend predictive effect of interest and engagement in learning science on scientific competency and environmental action.

- This study provides evidence that deeper engagements in museum and science-related informal learning resources can be critical venues for promoting public scientific competency and environmental action.

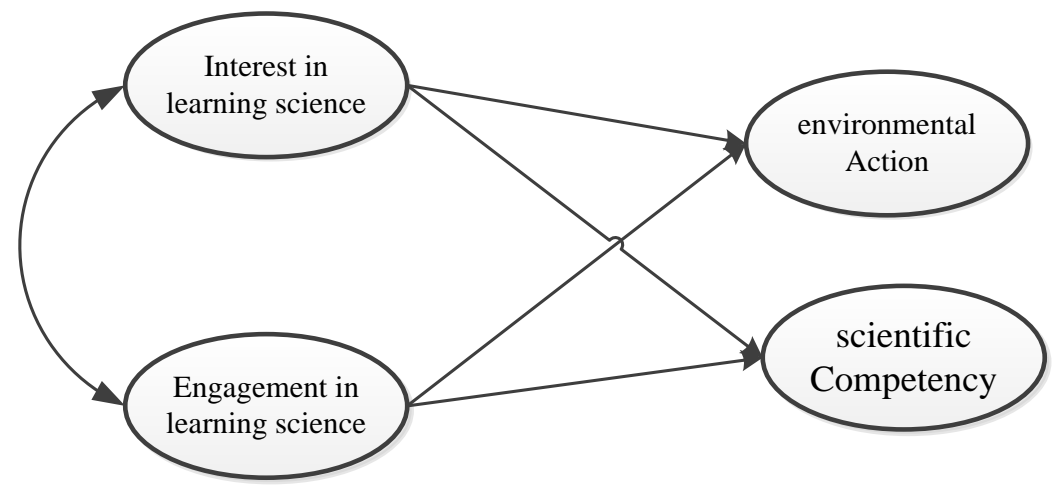

Figure 1. The theoretical model of Interest in learning science, Engagement in learning science, scientific Competency, and environmental Action (IECA)

$8^{\text {th }}$ grade students have learned cognitive skills taught in school (Mullis \& Martin, 2013). While studies using data from the Programme of International Student Assessment (PISA) have focused on assessing 15-year-old students' scientific competency in solving practical, real-life situations and problems (Organisation for Economic Cooperation and Development [OECD], 2013). Data from both TIMSS and PISA have been recognized as important sources of information which have produced many international studies and attracted a growing number of participating countries. Despite that large-scale studies investigating adults' scientific literacy have also been recognized as an important way to understand the general level of public understanding of and attitude toward science (National Science Board, 2010), there are few large-scale studies which have investigated citizen's science learning experience and its impact on scientific competency and environmental action.

Therefore, the focus of this study is not only to investigate how citizens' interest and engagement toward science learning synergistically interact with citizens' environmental action and scientific competency (Figure 1), but also to explore possible trends which took place during the 2012 and 2015 nation-wide civic science investigation cycles. The following research questions guided this study:

1. What are the relationships among interest in learning science, engagement in learning science, environmental action, and scientific competency?

2. How do the predictive effects of citizens' interest and engagement of learning science on scientific competency and environmental action vary between the 2012 and 2015 two nation-wide civic science investigation cycles?

\section{LITERATURE REVIEW}

\section{The Role of Interest in Learning Science}

Interest is understood as an affective factor which motivates a person's learning experiences in both formal and informal settings. Hidi and Renninger (2006) stated the importance of interest development and further concluded that individual interest has a powerful influence on learning processes. Along similar lines, Ainley and Ainley (2011) stated that students' general interest in science learning develops out from their previous learning experiences and expectations or predictions about their further science experiences. These researches point to the importance of both early science experiences and maintaining learners' feelings of fun and excitement while learning science. Therefore, a better understanding of adult interest in learning science would empower science educator provide appropriate learning programs motivating public citizen interest. 
In contrast to formal education settings, adults tend to use their leisure time in learning science-related topics that are generally motivated by their personal interest, curiosity, and need (Falk et al., 2007); seeking to fulfill their personal goals; improving their professional development and pursuing hobbies (Falk \& Dierking, 2013; Yamashita, López, Soligo, \& Keene, 2017). Consequently, we hypothesized that previous learning experiences and well-developed interest seem to have positive predictive effects and a driving force on adults' learning choices and their learning processes.

\section{Engagement in Learning Science}

There are three categories which allow one to understand the vast number of informal settings that developed in the National Research Council report "Learning Science in Informal Environments: People, Places, and Pursuits". These settings include everyday informal environments, such as watching TV, reading newspapers, magazines, searching online information, having conversations with friends, pursuing one's hobby in designed environments, such as museums, science centers, planetariums, aquariums, zoos, environmental centers, or libraries (National Research Council [NRC], 2009). No matter what the county a person is from, many people learn and obtain science and technology-related information from local or famous television programs, such as Discovery or the National Geography Channel (NSB, 2010; Wu et al., 2012). In Taiwan, half of the adult population is involved in learning science through watching science-related TV programs (Lin et al., 2012). According to surveys conducted in the UK, young people ages 14-18 were likely to be involved in outdoor science-related institutions with family members and indoor activities in school. More than half of young people have visited one science-related institution in the previous year, including zoos or aquariums, science museums, science discovery centers, and planetariums (Wellcome Trust Monitor, 2012). Despite that existing studies have explored ways of adults' science learning, few studies have investigated the impact of different learning resources on adults' learning outcome, especially through a way of cross-sectional large-scale studies.

Lin et al. (2012) compared public science engagement between 15-year-old students and adult citizens to explore and shed additional light on the role of interest, enjoyment, and engagement in science learning. Along similar lines, there is significant correlation between students' motivation, enjoyment, and engagement in the classroom and their future orientation towards learning science (Hampden-Thompson \& Bennett, 2013; Lin, Lawrenz, Lin, \& Hong, 2013). On the other hand, some research studies indicate that engagement or enjoyment in learning science is significantly related to the engagement in out-of-school activities (Uitto, Juuti, Lavonen, \& Meisalo, 2006). Grabau and Ma (2017) found that science engagement, such as motivation, enjoyment, personal value, and general value of science are significantly and positively related to science achievement. However, researchers advocate that learning outcomes in informal education represent a variety of different learning experiences. According to the Contextual Model of Learning modified by Falk and Dierking (2000), free-choice learning is constructed over time through the interactions between personal, sociocultural, and physical contexts. Their model demonstrates that learners' prior experiences and motivations influence their selections of free-choice learning.

Xiao (2013) investigated the interaction between public attitudes toward science and technology and environmental concern. Xiao's results show that general public has stronger faith in technological solutions to solve environmental problems, especially with concern to global environmental problems, than for technological solutions designed to solve local and national problems. The review of the above literature reveals that citizens' choice of their engagement in their leisure time learning may have a potential relationship with their environmental action.

\section{Scientific Competency and Environmental Action}

For the survey of adults, the public attitudes toward science and technology (PATSAT) (National Science Board, 2010) has been an important approach in understanding the level of scientific literacy of the general public. PATSAT was developed to monitor general public knowledge-attitude relationships on science and technology and provides the government with information for policy making. However, traditional knowledge-based measurements of adult scientific literacy, particularly measures based on what everyone "needs to know" or selected closed-ended science and technology-related knowledge questions are unduly narrow and restrictive. Such narrow and restrictive assessments are limited in measuring the impacts of school or out of school experiences (Falk et al., 2016; NRC, 2012).

One excellent source of information relative to the assessment of environmental action and scientific competency is the aforementioned Programme for International Student Assessment (PISA) (OECD, 2006, 2013). With the use of contextualized real-world test items, the PISA framework is designed to assess environmentalism and scientific competencies of explaining phenomena scientifically; Identifying scientific issues; and interpreting data and evidence scientifically (OECD, 2006). Despite that there have also been critical comments regarding some of the test items (Sadler \& Zeidler, 2009), PISA is not only a valid indicator of participants' abilities to participate in 
society, but also a powerful tool for countries to fine-tune their education policies (OECD, 2016). In view of the well-defined assessment framework of PISA, it was used to guide the development of scientific competency test items and environmental action survey questions.

Environmental action has been recognized as one of effective approaches for developing citizen capability and further contributing to environmental improvements. Frontline researchers found that young people's sense of hope and hopelessness were the main driving force for their environmental action (Wilks \& Harris, 2016). Additional significant determinants of environmental action include environmental concern, environmental knowledge, community responsibility, and personal locus of control (Fielding \& Head, 2012; Lo, 2016). Although considerable research has been devoted to exploring students' environmental action, limited studies have focused on adults' environmental action and their learning resources of environmental knowledge. The review of existing literature and findings highlight the need to gain a better understanding about how adults, who have mostly completed their formal education, can learn through informal educational resources such as museum and television.

In summary, affective factors (e.g., interest in learning science) and self-related cognition factors (e.g., engagement in learning science) have been identified as predictive factors in scientific literacy. Few studies, however, have investigated how these affective and cognitive factors toward science learning are related to adults' learning outcome. The focus of this study is to explore how these affective and cognition factors synergistically interact with adults' scientific competency and environmental action.

\section{METHODS}

\section{Background and Context of the Study}

The project of nation-wide survey for public citizen scientific literacy was recommended and initiated in the 2008 Taiwan national science and technology conference. The survey is intended to better understand the status of public scientific literacy for the purpose of formulating evidence-based national plan and policy of science education especially for adults. The first and the second survey were completed in 2012 and 2015 respectively.

\section{Participants}

In order to investigate possible trends effecting adults' scientific literacy, environmental action, and their science and technology learning experiences, this study investigated two cross-sectional datasets involving face-to-face interviews with public citizens in 2012 and in 2015. Two representative Taiwanese population samples of 1,831 and 1,863 with ages ranging from 18 to 70 years old participated in the two national assessment cycles respectively. This study used probability proportional to size (PPS) method to ensure that the sampled data were in proportion to the size of the general population. First, the whole population sampling has been divided the townships/district in Taiwan into six strata using cluster analysis by means of the following indicators: (1) population density, (2) education level, (3) percentage of the population over the age of 65 years, (4) percentage of the population aged 1564 years, (5) percentage of the industrial population, and (6) percentage of the service population. Second, subsampling conducted in three phases: (1) selecting specific districts by systematic sampling, (2) selecting the villages from these districts, and (3) selecting individuals from these villages to be interviewed. Third, in order to accommodate invalid samples and guarantee the target sample could be achieved, citizens' samples in each village were expanded by the (success + failure)/success ratios which were recommended by previous study (Wu et al., 2012). The expansion ratios estimated across the villages that ranged from 1.5 to 3.8 were used to conduct a sample list. The detail of stratified sampling processes and number of samples in each phase is shown in Table 1. This study used a part of the larger survey measure items to analyze the public understanding of science and technology between two cycles in 2015 and 2012. Among the effected participants, 1,595 and 1,808 of them successfully completed the questionnaire items which were the focus of this study. 
Table 1. Stratified proportion, PPS procedure, and completed samples on Taiwan's Public Scientific Literacy survey in 2015 and 2012

\begin{tabular}{|c|c|c|c|c|c|c|c|c|c|c|c|}
\hline \multirow[t]{2}{*}{ Stratum } & \multirow{2}{*}{$\begin{array}{l}\text { No. of } \\
\text { districts }\end{array}$} & \multicolumn{2}{|c|}{$\begin{array}{l}\text { Population } \\
\text { (proportion) }\end{array}$} & \multirow{2}{*}{$\begin{array}{c}\text { Phase } 1 \\
\text { towns }\end{array}$} & \multirow{2}{*}{$\begin{array}{l}\text { Phase } 2 \\
\text { villages }\end{array}$} & \multicolumn{2}{|c|}{$\begin{array}{l}\text { Phase } 3 \\
\text { citizens }\end{array}$} & \multicolumn{2}{|c|}{$\begin{array}{l}\text { Expanding } \\
\text { citizens }\end{array}$} & \multicolumn{2}{|c|}{$\begin{array}{l}\text { Completed } \\
\text { samples }\end{array}$} \\
\hline & & 2015 & 2012 & & & 2015 & 2012 & 2015 & 2012 & 2015 & 2012 \\
\hline 1 & 25 & $\begin{array}{c}3,564,655 \\
(0.221) \\
\end{array}$ & $\begin{array}{c}3,563,361 \\
(0.221) \\
\end{array}$ & 6 & 12 & 436 & 432 & 1,453 & 1,349 & 370 & 412 \\
\hline 2 & 40 & $\begin{array}{c}4,387,129 \\
(0.272) \\
\end{array}$ & $\begin{array}{c}4,366,758 \\
(0.271) \\
\end{array}$ & 8 & 16 & 544 & 512 & 1,722 & 1,500 & 493 & 465 \\
\hline 3 & 73 & $\begin{array}{c}4,480,267 \\
(0.277) \\
\end{array}$ & $\begin{array}{c}4,470,829 \\
(0.277) \\
\end{array}$ & 8 & 16 & 558 & 528 & 1,395 & 1,337 & 539 & 481 \\
\hline 4 & 47 & $\begin{array}{c}1,334,942 \\
(0.083) \\
\end{array}$ & $\begin{array}{c}1,292,408 \\
(0.080) \\
\end{array}$ & 2 & 4 & 160 & 160 & 317 & 336 & 158 & 164 \\
\hline 5 & 98 & $\begin{array}{c}1,718,978 \\
(0.106)\end{array}$ & $\begin{array}{c}1,778,179 \\
(0.110)\end{array}$ & 4 & 8 & 218 & 256 & 450 & 564 & 195 & 251 \\
\hline 6 & 75 & $\begin{array}{c}667,761 \\
(0.041) \\
\end{array}$ & $\begin{array}{c}660,604 \\
(0.041) \\
\end{array}$ & 2 & 4 & 84 & 96 & 161 & 240 & 76 & 90 \\
\hline Total & 358 & $16,153,732$ & $16,132,139$ & 30 & 60 & 2,000 & 1,984 & 5,498 & 5,326 & 1,831 & 1,863 \\
\hline
\end{tabular}

\section{Instruments}

The civic scientific literacy and understanding of science and technology questionnaire includes three dimensions: public interest and information sources in science, attitudes toward science and technology-related issues, and public understanding of science. The questionnaire was designed to investigate the current state of adult's scientific literacy and understanding of science and technology and provides empirical evidence for policy makers. This study used a part of the items from this questionnaire to investigate Interest in learning science, Engagement in learning science, scientific competency and environmental action (i.e., IEAC) for the purpose of a comparative analysis between 2012 and 2015 datasets.

Interest in learning science was measured by five scientific issue items. Respondents were asked to rate their interest level in these issues found in daily media news or available information channels on a four-point Likert scale of extremely not interested, not interested, interested, and very interested. The sample items are: "How interest are you in learning new scientific discoveries?" and "How interest are you in learning environmental preservation?" The possible total score of the five items is 20; a higher score represents higher interest in learning science.

Engagement in learning science was measured by the frequency of watching science-related TV programs and what type of institutions such as museums or science centers a respondent visited. The sample item which measured watching a TV program is: "How often do you watch science-related television programs?" Along with this question was a list of programs such as "national geography", "discovery" and several local TV science-related programs. Respondents were to indicate how often they watched each program. The sample item of visiting public institutions is: "How often do you visit natural science museum?" Each sample item had a Likert-type scale indicating five different levels of attendance. The five levels of watching TV programs within the past year are: $0=$ never, 1 = less than once a month, $2=$ once a month, $3=2-7$ times a month, $4=8$ times a month. On the other hand, the five levels of visiting public institutions in the past year are: $0=$ never, $1=$ once, $2=$ twice, $3=3$ times, $4=$ more than four times. Since the level of never is counted as zero, the possible total score of the 14 items is 56 ; a higher score represents higher levels of engagement in learning science.

Environmental Action contained six items asking how often the participants joined environment-related actions. Two sample items are "Have you ever expressed your own environmental views by attending a public hearing or a forum?" and "Have you ever worked in an environment-related volunteer?" The items are scored on a four-point scale, where " 4 " represents "Often" and " 1 " represents "Never". The possible total score of the 6 items is 24; a higher score reveals more environmental action.

Scientific Competency was measured by four test units containing a total of 9 and 10 items in 2015 and 2012 survey, respectively. One sample unit labelled as Environmental Quality contained a short contextual text introducing the zoology of earthworms in the environment. This sample unit consisted of three items. Each item contained a complex combination of three or four true-false statements. A combination of items is awarded 1 point when all true-false statements are answered correctly. Responses are summed, so that a higher score indicates higher scientific competency. 
The internal consistency of Cronbach's alpha for the variables of interest in learning science, engagement in learning science, and environmental action in 2015 were .753, .756, and .806; while these values in 2012 were .766, .775 , and .749 , respectively. Factor analysis was used to explore the construct validity of the measures and confirm the design structure. Factor loadings for each measurement item in 2015 and 2012, relating to the following indices are as follows: interest in learning science (five items $0.34-0.82 ; 0.37-0.87$ ), engagement in watching TV programs $(0.42 ; 0.53)$, engagement in visiting museums $(0.61 ; 0.61)$, environmental action (six items $0.58-0.83 ; 0.44-0.77)$, and scientific competency (four items $0.40-0.59 ; 0.37-0.56$ ). The $t$-values of all 17 items on the four variables were statistically significant $(p<.001)$. The results of satisfactory factor loadings support the validity claims about the measurement of the four variables in the questionnaire using reasonable approaches. Taking the "interest in learning science" as an example, it means that the five items measured for interviewees' interest in learning science could validly reflect this variable.

\section{Procedure}

For a better consistency and higher quality of survey, all investigators were trained by the research team through a one-day workshop to provide them with a complete understanding of the meaning of each questionnaire item and the standard procedures for conducting face-to-face interviews. Investigators were supervised by our research team during the survey period. Each citizen participant was interviewed for 30-50 minutes depending on the fluency and responding speed of the interviewer. The nation-wide face-to-face interview period was completed in one and half months. All of the interviewees' responses were protected by Taiwan's personal information protection act. In the 2015 survey, investigators used Computer Assisted Personal Interviewing (CAPI) for the first time as an assisting tool to interview the interviewees. CAPI is an application software which is used in small electronic devices, such as laptops or tablets. When the investigators used this tool during the interviews, the interviewees could type their responses directly on the screen and then their responses would be upload to the backend database to check the logical errors. The CAPI in this survey not only reduced the probability of transcription and avoided overusing paper, but also improved investigative efficiency and credibility.

\section{Statistical Analysis}

The structural equation modelling (SEM) analysis technique with maximum likelihood for path coefficient was used to test our hypothesized model (as Figure 1: the theoretical model of IECA. We hypothesize that adults' interest in learning science and engagement in learning science (independent variables) can predict their scientific competency and environmental action (dependent variables). The SEM was chosen because it has the benefits of less likely being biased than ordinary multiple regression (Nieswandt, 2007). It allows us to examine more than one independent variables simultaneously; and it is good for testing the causal relationships among variables (George \& Kaplan, 1998). Thus, the following section was presented the descriptive statistics, model fit condition, and the SEM models with path strengths. Additionally, an independent t-test was used to examine possible trends and differences between both 2012 and 2015 datasets, specifically on the participants' performance of interest in learning science, engagement in learning science and their environmental action.

\section{RESULT}

The means, standard deviation, and the correlation of measures for 2012 and 2015 datasets are shown in Table 2. For the 2015 dataset, it can be seen that citizens' environmental action and scientific competency are positively correlated with interest in learning science $(r=.27 ; r=.32)$ and engagement in learning science $(r=.32 ; r=.10)$; all $p$ values are less than .001 . For the 2012 dataset, citizens' scientific competency and environmental action are also positively correlated with interest in learning science $(r=.27 ; r=.28)$ and engagement in learning science $(r=.29 ; r$ $=.18)$; all $p$ values are less than .001 . 
Table 2. Correlation matrix, means, and standard deviations variables of 2015 and 2012 citizens' datasets

\begin{tabular}{|c|c|c|c|c|c|c|c|c|c|c|c|}
\hline & \multirow{2}{*}{ Variables } & \multicolumn{4}{|c|}{$2015^{b}$} & \multicolumn{6}{|c|}{$2012^{a}$} \\
\hline & & 1 & 2 & 3 & 4 & 5 & 1 & 2 & 3 & 4 & 5 \\
\hline 1. & Interest in learning science & 1 & $.20^{* \star}$ & $.27^{\star \star}$ & $.27^{\star \star}$ & $32^{* *}$ & 1 & $.29 * \star$ & $.25^{\star \star}$ & $.27^{\star \star}$ & $.28^{\star \star}$ \\
\hline 2. & $\begin{array}{l}\text { Engagement in watching } \\
\text { science-related TV } \\
\text { programs }\end{array}$ & & 1 & $.26^{\star *}$ & $.24^{\star *}$ & .01 & & 1 & $.34^{* *}$ & $.24^{\star *}$ & $.15^{* *}$ \\
\hline 3 & $\begin{array}{l}\text { Engagement in visiting } \\
\text { museums }\end{array}$ & & & 1 & $.30^{\star *}$ & $.20 * *$ & & & 1 & $.28^{\star *}$ & $.19^{* *}$ \\
\hline 4. & Environmental Action & & & & 1 & $.08^{\star *}$ & & & & 1 & $.09 * *$ \\
\hline 5. & scientific Competency & & & & & 1 & & & & & 1 \\
\hline & Mean $^{\mathrm{a}}$ & 13.70 & 4.40 & 2.31 & 7.71 & 5.00 & 14.10 & 10.89 & 1.98 & 7.17 & 7.37 \\
\hline & Standard Deviation & 2.34 & 4.80 & 2.63 & 2.74 & 1.92 & 2.25 & 6.69 & 2.44 & 2.20 & 1.92 \\
\hline
\end{tabular}

Note ${ }^{* \star} p<.001$

a: For 2015 dataset $(N=1595)$, the possible total score of variables $1,2,3,4$ and 5 are 20, 40, 16, 24 and 9 , respectively.

$b$ : For 2012dataset $(N=1808)$, the possible total score of variables $1,2,3,4$ and 5 are $20,40,16$, 24 and 10 , respectively.

\section{Model Fit Conditions}

The theoretical structure of IECA was estimated by exploring the paths among citizens' Interest in learning science, Engagement in learning science and their environmental Action and their performance of scientific Competency. This model has a reasonable model fit to the data in 2015 and 2012 datasets which is based on the results of several fit indicators, such as goodness-of-fit index $(\mathrm{GFI}=0.98$ and .99$)$, the comparative fit index (CFI= 0.96 and 0.98$)$; the standardized root mean square residual (SRMR $=.04$ and .03$)$, and the root mean square error of approximation (RMSEA = .04 and .03), respectively. According to Hu and Bentler (1995), the GFI and CFI with the value of larger than 0.90 were indicated a reasonable fit, the SRMR with the value of less than 0.05 is stated as a good model fit, and the value of RMSEA less than 0.05 can be considered as indicative of close fit. Thus, according to the aforementioned model fitness results for the 2015 dataset and the 2012 dataset, the IECA model demonstrated a good fit to the data in both datasets.

RQ1: What are the relationships among interest in learning science, engagement in learning science, environmental action, and scientific competency?

In order to explore citizens' trend performance from 2012 to 2015, statistical mean, standard deviation and independent $t$-test results for both cycles on interest in learning science, engagement in learning science (including watching science-related TV programs and visiting museums) and environmental action are presented in Table 3. First, trends in citizens' interest and engagement in watching science-related TV programs significantly decreased. The mean (14.10) of interest in learning science in 2012 is significantly higher than the mean (13.70) of interest in learning science in $2015(t=5.10, p<.001, d=0.18)$. Similarly, citizens' engagement in watching science-related TV programs in 2015 dramatically dropped with a mean score of 4.40 in 2015 as compared to the mean score of 10.89 in $2012(t=32.80, p<.001, d=1.12)$. On the other hand, the participants' level of engagement in visiting museums (mean $=2.31$ ) in 2015 has significantly higher than the participants' level of engagement in 2012 (mean=1.98, $t=3.87$, $p<.001, d=0.13)$. Finally, the trend in environmental action slightly increased. The environmental action of participants in 2015 (mean $=7.71$ ) was significantly higher than environmental action of participants in 2012 (mean $=7.18, t=6.27, p<.001, d=0.22)$.

RQ2: How are the predictive effects of citizens' interest and engagement of learning science on scientific competency and environmental action varied between the 2012 and 2015 two cycles of investigation?

The curve arrows in Figure 2 and Figure 3 represent correlation among variables and the straight arrows indicate the predictive path effects from independent variables to dependent variables. 
Table 3. Comparison of means and standard deviation of Interest in learning science, Engagement in TV science related program, Engagement in visiting museum and environment action for citizenships 2012 and 2015 datasets $(N=1,808 ; N=$ 1,595 , respectively)

\begin{tabular}{|c|c|c|c|c|c|c|c|c|}
\hline & Variables & Year & $M$ & $S D$ & $T$ & $p$ & ES & trend \\
\hline \multirow{2}{*}{\multicolumn{2}{|c|}{ 1. Interest in learning science }} & 2012 & 14.10 & 2.25 & \multirow{2}{*}{$5.10^{\star \star \star c}$} & \multirow{2}{*}{.000} & \multirow{2}{*}{0.18} & \multirow{2}{*}{$\Delta$} \\
\hline & & 2015 & 13.70 & 2.34 & & & & \\
\hline \multirow{2}{*}{2} & \multirow{2}{*}{$\begin{array}{l}\text { Engagement in science- } \\
\text { related TV programs }\end{array}$} & 2012 & 10.89 & 6.69 & \multirow{2}{*}{$32.80^{\star \star \star c}$} & \multirow{2}{*}{.000} & \multirow{2}{*}{1.12} & \multirow{2}{*}{$\nabla$} \\
\hline & & 2015 & 4.40 & 4.79 & & & & \\
\hline \multirow{2}{*}{3} & \multirow{2}{*}{$\begin{array}{l}\text { Engagement in visiting } \\
\text { museums }\end{array}$} & 2012 & 1.98 & 2.44 & \multirow{2}{*}{$-3.87^{* * * c}$} & \multirow{2}{*}{.000} & \multirow{2}{*}{0.13} & \multirow{2}{*}{$\lambda$} \\
\hline & & 2015 & 2.31 & 2.63 & & & & \\
\hline \multirow{2}{*}{\multicolumn{2}{|c|}{4 environment Action }} & 2012 & 7.18 & 2.20 & \multirow{2}{*}{$-6.27^{\star \star \star c}$} & \multirow{2}{*}{.000} & \multirow{2}{*}{0.22} & \multirow{2}{*}{$\nearrow$} \\
\hline & & 2015 & 7.71 & 2.74 & & & & \\
\hline
\end{tabular}

Note: ${ }^{* *} p<.001$

a: $d$ = effect size (Small 0.20; medium 0.50; large 0.80) (Cohen, 1988);

b: the possible total score of variable 1,2, 3 and 4 were 20,40, 16 and 24, respectively;

c: Levene's test of equality of variances indicates that these two samples cannot be assumed to have

statistically equal variances for the variable in the table.

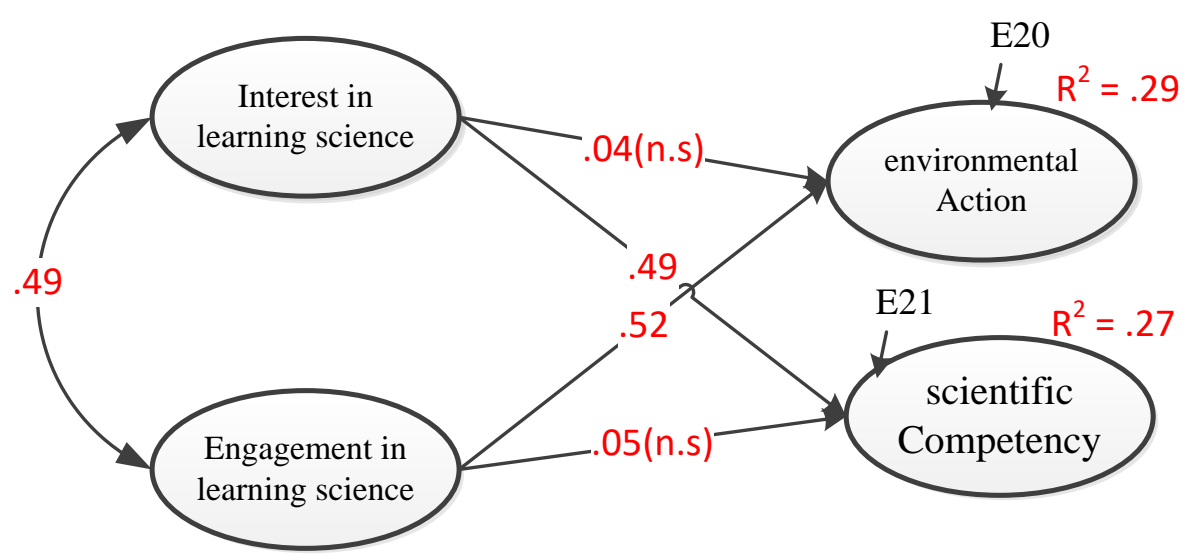

CMIN/DF=2.95, Df=111; GFI=.976; CFI=.964; SRMR=.0353; RMSEA=.035;

Figure 2. The tested model of IECA with the standardized coefficients in 2015 dataset $(N=1,595)$

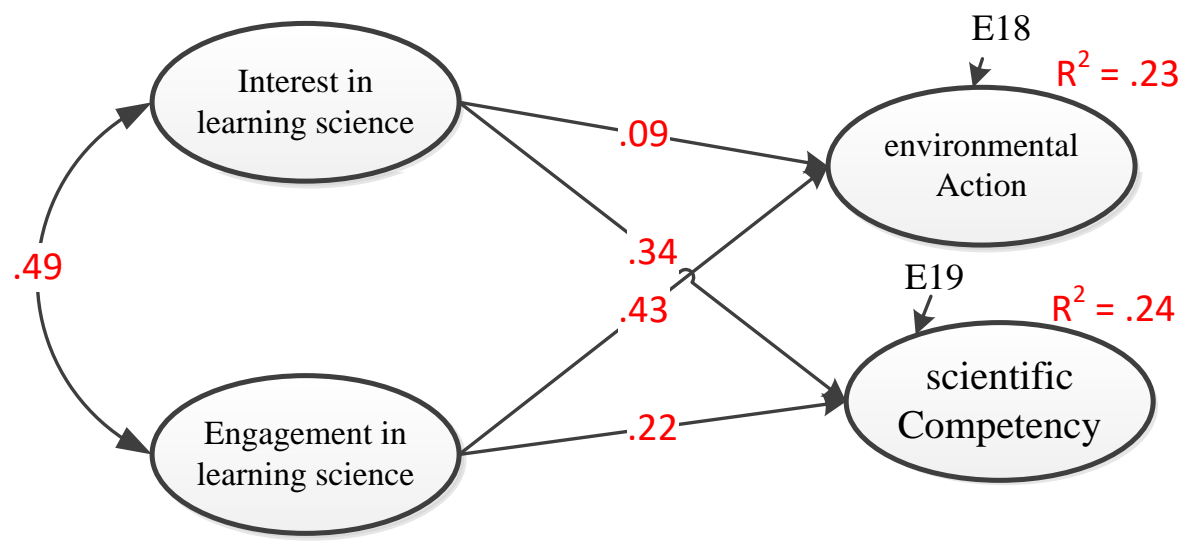

$\mathrm{CMIN} / \mathrm{DF}=2.127, \mathrm{Df}=112 ; \mathrm{GFI}=.985 ; \mathrm{CFI}=.979 ; \mathrm{SRMR}=.0325 ; \mathrm{RMSEA}=.025$;

Figure 3. The tested model of IECA with the standardized coefficients 2012 dataset $(N=1,808)$

Regression results $\left(\mathrm{R}^{2}\right)$ in this study indicated the percentage of variance accounted for the dependent variables (i.e. environmental actions and scientific competency) by the combined independent variables (Figure 2 and 3 ). An $R^{2}$ value summarizes the proportion of variance in the dependent variable which can be explained by the collective set of the predictors. The $\mathrm{R}^{2}$ results represent how citizens' interest and engagement in learning science can be predictive of their environmental actions and scientific competency. In 2015 dataset (as shown in Figure 2), the strongest effect of citizens' environmental action is predicted by the level of their engagement in learning science, with a standardized coefficient $(B)$ of .52 . It reveals that those people, who are more frequently engaged in learning 
science (either through watching science-related TV programs or visiting science museums), are more likely to stand up and take environmental action (e.g., attending public hearing or community meeting, reporting unlawful environmental behaviors, and donating money to non-profit environmental protection organizations). This result explains a total of $29.0 \%\left(R^{2}=.29\right)$ of the variance. On the other hand, interest in learning science is the strongest explanatory factor for citizens' scientific competency performance $(\beta=.49)$ when compared to the factor of engagement in learning science $(B=.05, \mathrm{n} . \mathrm{s})$. This result explains a total of $27.0 \%\left(\mathrm{R}^{2}=.27\right)$ of the variance.

For the 2012 dataset (as shown in Figure 3), citizens' environmental action is significantly explained by engagement in learning science $(\beta=.43)$, followed by interest in learning science $(\beta=.09)$. The total of variance explained by the two independent variables is $23 \%$. The second dependent variable, citizens' performance of scientific competency, can be significantly predicted by the factors of interest in learning science $(\Omega=.34)$ and engagement in learning science $(\beta=.22)$ with a total variance of $24 \%$.

As we compared Figures 2 and 3, it reveals that both "interest in learning science" and "engagement in learning science" are no longer predictive to "environmental action" and "scientific competency" respectively in the 2015 model (i.e., Figure 2) while the two independent variables are significantly predictive in the 2012 model (i.e., Figure 3). On the other hand, the "engagement in learning science" has become a stronger determinant of "environmental action while the "interest in learning science" has a higher predictive effect on "scientific competency" in 2015 model when it is compared with the 2012 model. These results not only shed light on the importance of engaging public citizens in learning science if environmental educators intend to promote public environmental awareness and positive actions, but also strengthens our understanding about how the two independent variables (i.e., interest and engagement in learning science) play critical but different roles on their predictive effects on scientific competency and environmental action, respectively.

\section{DISCUSSION}

This study adds value to the literature on environmental education and has policy implications concerning the effectiveness of informal science and environmental education. Previous studies have suggested the importance of using field trips to museums and other informal learning resources as supportive venues of classroom learning (Bell et al., 2009; Falk \& Dierking, 2000). The significant predictive effect of engagement in learning science on public citizens' scientific competency and environmental action especially contributed by visiting museums and sciencerelated learning resources (e.g., aquarium, science center, or national park) strengthens our understanding about its superior potential benefit compared to the popular science communication venue of watching television. Despite that science and environmental educators have devoted their efforts in developing TV programs to motivate public interest and engagement in learning science, unfortunately, the result of this study reveals that these TV programs have attracted less frequent viewers in 2015 than those of 2012. On the other hand, the visitors of science-related museums, centers, and parks have significantly increased in the same period of time. Additional trend predictive effect comparisons between 2012 and 2015 data sets reveal that there is significant increase of predictive effect by engagement in learning science on scientific competency and environmental action. The potential benefits of visiting science-related museum, center, and park can be partially explained by the findings of previous studies indicating the advantages of learning activities such as hands-on opportunities (Jack \& Lin, 2017; Lin et al., 2013), social interactions among visitors, museum educators, and science teachers (Davidson, Passmore, \& Anderson, 2010) and the engagement in writing worksheets (Krombaß \& Harms, 2008). The above results along with the significant increases of trend predictive effects of engagement in learning science to scientific competency and environmental action seem to remind educators and policy makers that more efforts and financial support need to be focused on the development of museum learning resources.

One of the noteworthy findings of the study is that engagement in learning science is more predictive to scientific competency and environmental action than the predictive effect of interest in learning science. This result does not mean that interest in learning science emphasized by frontline researchers (e.g., Jack et al., 2014, 2017; Lin et al., 2012, 2013; Palmer, 2004) is no longer important. Instead, it reveals that as soon as learners' interest is triggered, follow-up engagements of deep-learning such as learning opportunities enabling dialectical nature of mediation (Sakellari, 2015), transdisciplinary connection, mediated engagement, meaningful discovery, and selfdetermined inquiry (Jack et al., 2017) play a critical role in promoting their long-term scientific competency and environmental action. One possible implication of this finding is that when learners' interest is triggered by the exhibitions, demonstrations, or aesthetic perceptions, well-designed follow-up learning opportunities such as dynamic interactions between the learning resources and the learner or reflective evaluation on the learning content and context (e.g., Lin, Hong, Chen, \& Chou, 2011; Lin et al., 2012) are more likely to promote learners' advance learning outcomes. Therefore, future studies using experimental designs to explore effective strategies of promoting learning engagement and outcomes are recommended.

The second noteworthy finding of the study is the significant decline of public interest in learning science. The alarming t-test result reveals that there is a significant decrease of public citizens' interest in learning science 
between the two cycles. One possible reason for this is a mismatch between the existing learning resources and the expected learning programs for public citizens. For instance, even though low performing TV programs have been replaced by newly developed programs, such replacements do not result in attracting more frequent viewers. Future research studies are recommended to explore the unique characteristics of high quality or award-winning TV programs that are capable of attracting frequent viewers with deeper engagement in learning.

\section{LIMITATIONS}

There are several limitations to the study. First of all, the predictive effect results do not indicate a causal effect between the independent and dependent variable. In other words, the correlational predictive effect of museum visit does not include the quality data of strategies and characteristics of effective museum visits. It would be useful for future research to conduct experimental studies exploring the design and effectiveness of museum learning programs. In addition, the results of these national datasets might not be broadly generalizable to other countries because of the contextual and cultural differences. Additional comparisons of international cross-cultural studies investigating the potential effects of museum learning engagement on visitors' emotional and cognitive learning outcome are recommended.

\section{CONCLUSION}

By comparing two cycles of national datasets on public citizens' interest and engagement in learning science, scientific competency, and environmental action, the results of this study provide fresh insights into the changing pattern and trend predictive effect of interest and engagement in learning science on scientific competency and environmental action. The significant decrease of public citizens' interest in learning science deserves a special attention and consideration from educators to develop effective informal learning resources that are capable of triggering public interest in science. In addition, this study provides evidence that engagements in museum and science-related informal learning resources and experiences can be critical venues for promoting public scientific competency and environmental action.

\section{ACKNOWLEDGEMENTS}

This study was supported by the Ministry of Science and Technology, Taiwan under grant MOST 105-2511-S110-001-MY4.

\section{REFERENCES}

Ainley, M., \& Ainley, J. (2011). Student engagement with science in early adolescence: The contribution of enjoyment to students' continuing interest in learning about science. Contemporary Educational Psychology, 36(1), 4-12. https:/ / doi.org/10.1016/j.cedpsych.2010.08.001

Ballantyne, R., \& Packer, J. (2011). Using tourism free-choice learning experiences to promote environmentally sustainable behavior: the role of post-visit 'action resources'. Environmental Education Research, 17(2), 201215. https:// doi.org/10.1080/13504622.2010.530645

Bell, P., Lewenstein, B., Shouse, A., \& Feder, M. (2009). Learning science in informal environments: People, places, and pursuits. Washington: National Academies Press.

Davidson, S. K., Passmore, C., \& Anderson, D. (2010). Learning on zoo field trips: The interaction of the agendas and practices of students, teachers, and zoo educators. Science Education, 94, 122-141.

Falk, J. H., \& Dierking, L. D. (2000). Learning from museums. Walnut Creek, CA: Altamira Press.

Falk, J. H., \& Dierking, L. D. (2013). The museum experience revisited. Walnut Creek, CA: Left Coast Press.

Falk, J. H., Dierking, L. D., Staus, N., Wyld, J., Bailey, D., \& Penuel, W. (2016). The Synergies research-practice partnership project: A 2020 Vision case study. Cultural Studies of Science Education, 11(1), 195-212. https:/ / doi.org/10.1007/s11422-015-9716-2

Falk, J. H., Storksdieck, M., \& Dierking, L. D. (2007). Investigating public science interest and understanding: Evidence for the importance of free-choice learning. Public Understanding of Science, 16, 455-469. https:/ / doi.org/10.1177/0963662506064240

Fielding, K. S., \& Head, B. W. (2012). Determinants of young Australians' environmental actions: the role of responsibility attributions, locus of control, knowledge and attitudes. Environmental Education Research, 18(2), 171-186. https:/ / doi.org/10.1080/13504622.2011.592936 
George, R., \& Kaplan, D. (1998). A structural model of parent and teacher influences on science attitudes of eighth graders: Evidence from NELS: 88. Science Education, 82(1), 93-109. https://doi.org/10.1002/(SICI)1098237X(199801)82:1<93::AID-SCE5>3.0.CO;2-W

Grabau, L. J., \& Ma, X. (2017). Science engagement and science achievement in the context of science instruction: a multilevel analysis of U.S. students and schools. International Journal of Science Education, 39(8), 1045-1068. https:/ / doi.org/10.1080/09500693.2017.1313468

Hampden-Thompson, G., \& Bennett, J. (2013). Science teaching and learning activities and students' engagement in science. International Journal of Science Education, 35(8), 1325-1343. https:/ / doi.org/10.1080/09500693.2011.608093

Hidi, S., \& Renninger, K. A. (2006). The four-phase model of interest development. Educational Psychologist, 41(2), 111-127. https://doi.org/10.1207/s15326985ep4102_4

Hu, L. T., \& Bentler, P. M. (1995). Evaluating model fit. In H. RH (Ed.), Structural Equation Modeling: Concepts, Issues, and Applications. (pp. 76-99). Thousand Oaks, CA: Sage.

Jack, B. M., \& Lin, H. S. (2017). Making learning interesting and its application to the science classroom. Studies in Science Education, 53(2), 137-164. https:/ / doi.org/10.1080/03057267.2017.1305543

Jack, B. M., Lin, H. S., \& Yore, L. (2014). The synergistic effect of affective factors on student learning outcomes. Journal of Research in Science Teaching, 51(8), 1084-1101. https:/ / doi.org/10.1002/ tea.21153

Krombaß, A., \& Harms, U. (2008). Acquiring knowledge about biodiversity in a museum- Are worksheets effective? Journal of Biological Science, 42(4), 157-163.

Lin, H. S., Hong, Z. R., \& Huang, T. C. (2012). The role of emotional factors in building public scientific literacy and engagement with science. International Journal of Science Education, 34(1), 25-42. https:/ / doi.org/10.1080/09500693.2010.551430

Lin, H. S., Hong, Z. R., Chen, C. C. \& Chou, C. H. (2011). The effect of integrating aesthetic understanding in reflective inquiry activities. International Journal of Science Education, 33(9), 1199-1217. https:/ / doi.org/10.1080/09500693.2010.504788

Lin, H., Lawrenz, F., Lin, S., \& Hong, Z. (2013). Relationships among affective factors and preferred engagement in science related activities. Public Understanding of Science, 22(8), 941-954. https://doi.org/10.1177/0963662511429412

Lo, A. Y. (2016). National income and environmental concern: Observations from 35 countries. Public Understanding of Science, 25(7), 873-890. https:/ / doi.org/10.1177/0963662515581302

Mullis, I. V. S., \& Martin, M. O. (Eds.). (2013). TIMSS 2015 Assessment Frameworks. Retrieved from http:/ / timssandpirls.bc.edu/timss2015/frameworks.html

National Research Council (NRC). (2009). Learning science in informal environments: People, Places, and Pursuits. Washington, DC: The National Academies Press.

National Research Council (NRC). (2012). A Framework for K-12 Science Education: Practices, Crosscutting Concepts, and Core Ideas. Committee on a Conceptual Framework for New K-12 Science Education Standards. Board on Science Education, Division of Behavioral and Social Sciences and Education. Washington, DC: The National Academies Press.

National Science Board (NSB). (2010). Science and engineering indicators-2010. Arlington, VA: National Science Foundation. Retrieved from http:/ / www.nsf.gov/statistics/seind10/

Nieswandt, M. (2007). Student affect and conceptual understanding in learning chemistry. Journal of Research in Science Teaching, 44(7), 908-937. https:/ / doi.org/10.1002/ tea.20169

Organisation for Economic Co-operation and Development (OECD). (2013). PISA 2015 draft science framework. Paris, France: Author.

Organisation for Economic Co-operation and Development (OECD). (2016). PISA 2015 results- Excellence and equity in education volume 1. Paris, France: Author.

Organisation for Economic Co-operation and Development (OECD).(2006). Assessing scientific, reading and mathematical literacy: A framework for PISA 2006. Paris, France: Author.

Palmer, D. (2004). Situational interest and the attitudes towards science of primary teacher education students. International Journal of Science Education, 26(7), 895-908. https:/ / doi.org/10.1080/0950069032000177262

Sadler, T. D., \& Zeidler, D. L. (2009). Scientific literacy, PISA, and socioscientific discourse: Assessment for progressive aims of science education. Journal of Research in Science Teaching, 46(8), 909-921. https:/ / doi.org/10.1002/ tea.20327 
Sakellari, M. (2015). Cinematic climate change, a promising perspective on climate change communication. Public Understanding of Science, 24(7), 827-841. https:/ / doi.org/10.1177/0963662514537028

Stapleton, S. R. (2015). Environmental identity development through social interactions, actions, and recognition. The Journal of Environmental Education, 46(2), 94-113. https:/ / doi.org/10.1080/00958964.2014.1000813

Su, Y. S., Ding, T. J., \& Lai, C. F. (2017). Analysis of students engagement and learning performance in a social community supported computer programming course. Eurasia Journal of Mathematics, Science and Technology Education, 13(9), 6189-6201. https:/ / doi.org/10.12973/eurasia.2017.01058a

Uitto, A., Juuti, K., Lavonen, J., \& Meisalo, V. (2006). Students' interest in biology and their out-of-school experiences. Journal of Biological Education, 40(3), 124-129. https:/ / doi.org/10.1080/00219266.2006.9656029

Wellcome Trust Monitor. (2012). Wellcome Trust Monitor 1: Wellcome Trust Monitor Survey report. Retrieved from https://wellcome.ac.uk/sites/default/files/monitor-wave1-wellcome-sep09.pdf

Wilks, L., \& Harris, N. (2016). Examining the conflict and interconnectedness of young people's ideas about environmental issues, responsibility and action. Environmental Education Research, 22(5), 683-696. https:/ / doi.org/10.1080/13504622.2015.1054261

Wu, K. C., Shein, P.P., Tsai, C. Y., Chou, C. Y., Wu, Y. Y., Liu, . . Huang, T. C. (2012). An Investigation of Taiwan's Public Attitudes toward Science and Technology. International Journal of Science Education, Part B: Communication and Public Engagement, 2(1), 1-21. https:/ / doi.org/10.1080/21548455.2011.613643

Xiao, C. (2013). Public attitudes toward science and technology and concern for the environment. Environment and behavior, 45(1), 113-137. https:/ / doi.org/10.1177/0013916511414875

Yamashita, T., López, E. B., Soligo, M., \& Keene, J. R. (2017). Older lifelong learners' motivations for participating in formal volunteer activities in urban communities. Adult Education Quarterly, 67(2), 118-135. https://doi.org/10.1177/0741713616688957

\section{http://www.ejmste.com}

